\title{
How to design a blended method to teach BLS-AED for undergraduate nursing and medical education
}

\author{
Jordi Castillo*1,2, Laura Martinez ${ }^{3}$, M.Angels Martinez ${ }^{4}$, Alicia Melero ${ }^{5,6}$, Enrique Moret ${ }^{5,6}$, Mònica Rodríguez \\ ${ }^{1}$ Universitat Internacional de Catalunya, Barcelona, Spain \\ ${ }^{2}$ Hospital Universitari de Bellvitge, Hospitalet de Llobregat, Barcelona, Spain \\ ${ }^{3}$ Department of Obstetrics and Ginecology, Hospital del Mar, Barcelona, Spain \\ ${ }^{4}$ Department of Obstetrics and Ginecology, Hospital Clínic de Barcelona, Barcelona, Spain \\ ${ }^{5}$ Hospital Universitari Germans Trias i Pujol. Barcelona, Spain \\ ${ }^{6}$ Universitat Autonoma de Barcelona, Barcelona, Spain \\ ${ }^{7}$ Mútua laboral MC-Mutual, Barcelona, Spain \\ ${ }^{8}$ Col-legi de Fisioterapeutes de Catalunya, Barcelona, Spain
}

Received: January 5, 2019

DOI: $10.5430 /$ jnep.v9n8p11
Accepted: April 3, 2019

Online Published: April 18, 2019

\begin{abstract}
New technology can help to spread knowledge and skills related to cardiopulmonary resuscitation. Historically, virtual methods have not been strongly recommended for Consell Català de Resuscitació (CCR), but many authors have begun to investigate new methods for achieving lower costs, widespread distribution, increased accessibility to information and more frequent updates of content. Moodle platforms, videos, web pages and other technologies have been introduced in the learning world. The authors posit that a blended approach of traditional methods with virtual methods without moving away from standard recommendations could facilitate the introduction of these new methods into our teaching practice. In this article, the authors present how to design a blended method. The first pilot test was designed with undergraduate medical and nursing students in their fourth year. Their suggestions led the authors to use the Moodle platform of their University as a conductive thread. A second pilot with non-students led to the need for a website where the learners could find the videos with e-learning content. Three videos were seen during the practice time. The debate notes the need for having an official method of blended or virtual approaches to teach Cardiopulmonary Resuscitation (CPR) in an efficient and cost-saving way.
\end{abstract}

Key Words: E-Learning, Blended method, Undergraduate nursing, Medical education

\section{INTRODUCTION}

Although the term "e-Learning" sometimes refers to blended interventions involving electronic systems and face-to-face teaching, it is generally seen as a particular evolution of distance education, that is, the use of information technologies in order to deliver education to remote learners. ${ }^{[1]}$

The delivery advantages of an e-Learning programme are ob- vious: some of their most cited benefits include lower costs, widespread distribution, increased accessibility to information, frequent content updates and personalised instruction in terms of content and pace of learning. ${ }^{[2]}$

Potential disadvantages include technology-related costs, cost involved in developing programmes, possible technical problems, limited direct interaction, lack of exchanges

\footnotetext{
*Correspondence: Jordi Castillo; Email: jordicastillogarcia@gmail.com; Address: Hospital Universitari de Bellvitge, Hospitalet de Llobregat, Barcelona, Spain.
} 
and relations with other learners, absence of the physical presence of the teacher, decrease in motivation to learn, need for greater self-discipline, and attenuation of the desire to compete with other learners. ${ }^{[3,4]}$

Traditional learning may be preferable in some instances, e.g. to improve knowledge or skills in small groups of health professionals when physical attendance is feasible, while e-Learning programmes may be a better choice when the aim is to reach a large number of health professionals at a limited cost. Blended courses potentially balance the benefits of the two learning strategies. ${ }^{[5]}$

E-Learning-based on virtual education methodology, virtual and online learning in basic life support (BLS) and automated external defibrillator (AED) courses are exponentially increasing but no specific method is recommended yet by the international institutions.

The European Resuscitation Council (ERC) Guidelines have progressively highlighted, since 2005 , that BLS-AED training using methods other than face-to-face can be an effective alternative. ${ }^{[6]}$

In 2010, the idea of introducing new methods appeared: "BLS skills can be learned equally well with "practice by watching" (Video based) training as through longer traditional instructor-led courses". [7]
In 2015, guidelines accepted that blended learning packages for life support courses on e-Learning basis programmes with abbreviated instructor-led training had been shown to be equivalent to standard training for advanced life support courses but no method was recommended. ${ }^{[8]}$

Blended training must be of a quality that is comparable to traditional training in order to achieve at least the same effectiveness in learning. There is no recommended model to use and no validated model allows comparison to traditional methods. Most of the studies published to date compare final results introducing new methods or technological devices. The main aim of our study is to present a new design for a blended method, the efficacy of which has been already proved by the author when compared to traditional learning. [9]

\section{SETTING THE DESIGN}

Before starting on the design of the course, we looked at all the research that had achieved good results when comparing virtual and blended training with traditional learning.

With the aim to compare traditional and blended methodology, our design followed the same chronology as a standardised course regarding knowledge, practice and evaluation times (see Figure 1).

\begin{tabular}{|c|c|c|c|}
\hline \multicolumn{2}{|c|}{$\begin{array}{l}\text { TRADITIONAL SCHEDULE OF A BLS-AED COURSE } \\
6 \text { hours }\end{array}$} & FACE-TO-FACE TRAINING & BLENDED TRAINING \\
\hline \multicolumn{2}{|r|}{15 days before the course } & \multicolumn{2}{|c|}{ Presentation and delivery of the handbook } \\
\hline TIMETABLE & PROGRAMME & CLASSROOM & CLASSROOM \\
\hline $8: 30-8: 40$ & Welcome. Presentation & \multirow[b]{3}{*}{ Big classroom Ratio Teacher/student: 1/16 } & \multirow{3}{*}{$\begin{array}{l}\text { Computer classroom. Videos in Moodle and } \\
\text { web platform. No instructor }\end{array}$} \\
\hline $8: 40-8: 50$ & Initial Evaluation & & \\
\hline $8: 50-9: 30$ & BLS-AED theory & & \\
\hline \multirow[t]{2}{*}{ 9:30-10:00 } & \multicolumn{3}{|c|}{ BREAK } \\
\hline & GROUPS A/B & GROUP A/B & GROUP B/C \\
\hline $10: 00-11: 30$ & BLS skill abilities "step by step" & \multirow{4}{*}{$\begin{array}{l}\text { CLASSROOM PRACTICES Ratio } \\
\text { Teacher/student: } 1 / 8\end{array}$} & \\
\hline $11: 30-12: 00$ & AED skill abilities "step by step" & & $\begin{array}{l}\text { PRACTICES CLASSROOM. } 8 \text { students/manikin } \\
\text { without instructor }\end{array}$ \\
\hline $12: 00-12: 45$ & \multirow{2}{*}{ Integrated simulations } & & \\
\hline $12: 45-13: 30$ & & & INSTRUCTOR \\
\hline \multirow{2}{*}{$13: 30-14: 30$} & Knowledge Evaluation & BIG CLASSROOM & COMPUTER CLASSROOM \\
\hline & Skill Evaluation & \multicolumn{2}{|c|}{ SIMULATION CLASSROOM } \\
\hline
\end{tabular}

Figure 1. Chronology of the blended course using our designed method

Before implementing a new method, we thought we should ask the opinion of the students to whom the course was addressed and also of external people whose objective advice could be useful in the design of our blended course.

\subsection{First pilot}

With a basic initial scheme on virtual training, a first pilot test was designed with undergraduate nursing students in their fourth year. We used a MS Word text with hyperlinks. 
Clicking on them, the students were guided to the videos on BLS-AED which replaced the face-to-face lectures recommended on the BLS course based on the 2010 guides, ${ }^{[7]}$ and a practice of 30 minutes to nursing students. The students had to watch three videos and then perform the "step by step" manoeuvres on the manikins located on the floor.

At the end of this first pilot, a questionnaire was distributed. Sixty students were encouraged to critique the dynamics of the group and the method.

We realized that two important elements should be changed:

First, students found that the hyperlink system was not quick or accurate enough. Their suggestions led us to use the Moodle platform of our University as a conductive thread, but this platform did not tolerate the size of the videos. Our university only allows $45 \mathrm{MB}$ per subject, and one of the three videos alone employed $600 \mathrm{MB} \cdot{ }^{[10]}$

To address the suggestions of the students and the difficulties with the videos, we asked for help from the Information and Communication Techniques (ICT) Department whose coordinator launched an official course called "Research of Virtual Support."

We decided then to set up a website where the learners could find the e-Learning video content. From the main page, students could access the menu bar which guided them to different segments of the course, and they could reach the links with their own passwords.

Second, 60 students said that they could not ask questions and did not know if their manoeuvres on the manikins were properly executed. This question gave us the idea of a forum blog where they could ask questions of the instructor and be seen by all the students.

Before being accepted by the Undergraduate Committee, a second pilot study was conducted to check the efficacy and ease of the platform.

\subsection{Second pilot}

To confirm the efficacy and comprehension of the whole blended design with the changes made after the first pilot, we designed a second pilot. In this case, there were no students. Participants were specifically selected: a nurse, associated professor of the University, instructor of BLS-AED from the local Committee of Cardiopulmonary Resuscitation (CPR) and trainer of trainers, two teachers, one of them a nurse with scarce knowledge in BLS but great expertise in teaching methodology, an anaesthesiologist, one of the founders of the ERC Local Committee, two nurses with some knowledge in BLS but no knowledge about teaching methodology, one medical student of the same University, one engineer and one

Published by Sciedu Press economist with no knowledge in BLS or teaching methodologies. We used the same methodology as in the first pilot with the same manikins and practice timing.

Some modifications in the methodology were suggested to improve the comprehension of the method. Other contributions concerned the design of the website or aesthetic aspects.

\section{IMPLEMENTATION}

Each participant received the BLS course manual two weeks before the course date.

E-learners were located in a computer classroom where they could find in their personal mail a link to the Moodle platform with the title "virtual space in BLS-AED".

On the main page, learners could find seven sub-tabs to follow consecutively along the training timeline. All pages were linked to a blog where students could ask questions to the instructor online.

The self-instruction practice was performed in a classroom provided with a manikin without automated feedback (Re-

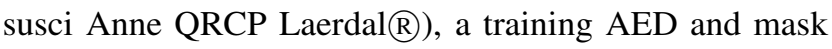
shields to perform hands-on practice. The audiovisual recordings with the four-stage method helped the learners to practice. ${ }^{[11]}$ Students were allocated to groups of eight. The relationship of manikins to learners was 1:2 because the practice by pairs is very useful during the acquisition of BLS skills. The instructor did not intervene in the scenario, but at the end of the practice and before the final evaluation, we decided to include some online instructor time in the virtual group (45 min) if students had any questions or doubts.

All candidates were assessed by a pre- and post-course Multi Chioce Questioons (MCQ). Skills were evaluated by an instructor using a practical clinical case or cardiac arrest, a checklist and the data from the high-fidelity manikin ventilation and cardiac compressions (Resusci Anne QRCP Laerdal $(R)$. A satisfaction survey was carried out at the end of the study with global results of 8.6 up to 10 .

\section{Discussion}

Many authors and instructors of BLS-AED have signed up for introducing virtual aspects in their courses. Video record of the simulation session was used by Bowden et al. ${ }^{[12]}$ (2012) and Moule et al. ${ }^{[13]}$ (2001) to enable learners to view all data for debriefing, assessment and evaluation.

Some authors, such as Vries et al. ${ }^{[14]}$ (2010), strongly recommend instruction comprising only short videos, with no instructor or even scenario presence, whereas other studies carried on without any instructor failed to obtain good results. Others have tried to manage the practice on a virtual training 
basis but without good results. ${ }^{[3]}$ Some authors have used video games to complement CPR instruction on a face-toface basis. ${ }^{[15]}$

Instructor presence at some point in the virtual training is a much discussed topic. For those who defend instructor presence, the presence time is variable, as low as 5 minutes in some cases. ${ }^{[16]}$

In response to these contradictory results, we have introduced 45 minutes of instructor time at the end of the practice. We think that his or her presence is important during the practice and essential at evaluation time. Nevertheless, our students did not ask for much help from the instructor during the practice time, probably because videos and peer-learning provided enough and clear information.

The Moodle platform has been used in different settings and seems to be useful, but no institutional model has been recommended. ${ }^{[10,17]}$

High-fidelity manikins with feedback are widely accepted as a method for evaluating manoeuvres such as ventilation and cardiac compressions. ${ }^{[18]}$

If we want students to engage, we will have to combine fun with learning, use multi-media technology and integrate teamwork in this process. That is what we have done with the practice by pairs, where students change roles and interact with one another. ${ }^{[19-21]}$

Our programme has substituted a Web-based video for the teacher in the teaching of cardiopulmonary resuscitation. Presently, master classes tend to bore the students and are not cost-effective. Many authors and instructors of BLSAED could take advantage of a well-designed method that provides solutions to the difficulties we have found.

Many efforts and many ideas have been proposed, but so far, no model has been accepted by the international community. We propose that this very easy method should be introduced in undergraduate medical and nursing education.

\section{Conflicts of Interest Disclosure}

No conflict of interest declared.

\section{REFERENCES}

[1] Liu Q, Peng W, Zhang F, et al. The Effectiveness of Blended Learning in Health Professions: Systematic Review and Meta-Analysis. Journal of Medical Internet Research. 2016; 18(1): e2.

[2] Wentling T, Waight C, Gallaber J, et al. E-learning-a review of literature. (Report No. ED-RR-89-3). Urbana-Champaign, Knowledge and Learning Systems Group. 2000.

[3] Cook D, Levinson A, Garside S, et al. Internet-Based Learning in the Health Professions: A Meta-analysis. JAMA. 2008; 300(10): 118196. PMid:18780847 https://doi .org/10.1001/jama.300.10. 1181

[4] Welsh E, Wanberg C, Brown K, et al. E-learning: emerging uses, empirical results and future directions. International Journal of Training and Development. 2003; 7(4): 245-58. https://doi.org/10.104 6/j.1360-3736.2003.00184.x

[5] Vaona A, Banzi R, Kwag KH, et al. E-learning for health professionals (Review). Cochrane Database of Systematic Reviews. 2018.

[6] Baskett P, Nolan J, Handley A, et al. European Resuscitation Council Guidelines for Resuscitation. Section 9. Principles of training in resuscitation. Resuscitation. 2005.

[7] Nolan J, Soar J, Zidemanc D, et al. European Resuscitation Council Guidelines for Resuscitation 2010 Section 1. Resuscitation. 2010; 81: 1219-76. PMid:20956052 https://doi .org/10.1016/j.re suscitation.2010.08.021

[8] Monsieurs K, Nolan J, Bossaert L, et al. European Resuscitation Council Guidelines for Resuscitation 2015 Section 1. Resuscitation 2015; 95: 1-80. PMid:26477410 https://doi.org/10.1016/j resuscitation.2015.07.038

[9] Castillo J, Gallart A, Rodriguez E, et al. Basic life support and external defibrillation competences after instruction and at 6 months comparing face-to-face and blended training. Randomised trial. Nurse Education Today. 2018.
[10] Casales R, Castro J, Hechavarría G. Algunas experiencias didácticas en el entorno de la plataforma Moodle. Revista de Informática Educativa y Medios Audiovisuales. 2008; 5(10): 1-10.

[11] Handley J, Handley A. Four-step CPR-improving skill retention. Resuscitation. 1998; 36: 3-8. https://doi.org/10.1016/S030 0-9572 (97) 00095-6

[12] Bowden T, Rowlands A, Buckwell M, et al. Web-based video and feedback in the teaching of cardiopulmonary resuscitation. Nurse Education Today. 2012; 32: 443-447. PMid:21546137 https: //doi.org/10.1016/j.nedt.2011.04.003

[13] Moule P, Gilbert P, Chalk V. A multimedia approach to teaching basic life support - the development of a CD-ROM. Nurse Education in Practice. 2001; 1(2): 73-9. PMid:19036247 https: //doi.org/10.1054/nepr.2001.0013

[14] DeVries W, Turner NM, Monsieurs KG, et al. Comparison of instructor-led automated external defibrillation training and three alternative DVD-based training methods. Resuscitation. 2010; 81(8): 1004-9. PMid:20483519 https://doi.org/10.1016/j.resusc itation.2010.04.006

[15] Boada I, Rodríguez-Benítez A, Garcia-González JM, et al. Using a serious game to complement CPR instruction in a nurse faculty, Comput Methods. Programs Biomed. 2015; 122(2): 282-91. PMid:26319184 https://doi.org/10.1016/j.cmpb.2015.08.006

[16] LeFlore JL, Anderson M, Michael JL, et al. Comparison of selfdirected learning versus instructor-modeled learning during a simulated clinical experience. Simulation in Healthcare. 2007; 2: 170-7. PMid:19088620 https://doi.org/10.1097/SIH. 0b013e3181 $2 \mathrm{dfb} 46$

[17] Cordero J, Caballero A. La plataforma Moodle: Una herramienta útil para la formación en soporte vital. Atención Primaria. 2015; 47(6): 376-84. PMid:25934346 
[18] Kirkbright S, Finn J, Tohira H, et al. Audiovisual feedback device use by health care professionals during CPR: A systematic review and meta-analysis of randomized and non-randomized trials. Resuscitation. 2014; 85(4): 460-71. PMid:24361457 https: //doi.org/10.1016/j.resuscitation.2013.12.012

[19] Harvey P, Higenbottam C, Owec A, et al. Peer-led training and assessment in basic life support for healthcare students: Synthesis of literature review and fifteen years practical experience. Resuscitation. 2012; 83(7): 894-9. PMid:22285723 https://doi.org/10.101 6/j.resuscitation.2012.01.013

[20] Iserbyt P, Elen J, Behets D. Peer evaluation in reciprocal learning with task cards for acquiring Basic Life Support (BLS). Resuscitation. 2009; 80(12): 1394-8. PMid:19900743 https://doi.org/10.1 016/j.resuscitation. 2009.07.006

[21] Williams B, Olaussen A, Peterson E. Peer-assisted teaching: An interventional study. Nurse Education in Practice. 2015; 15(4): 293-8 PMid:25866358 https://doi.org/10.1016/j.nepr.2015.03 .008 